\title{
Post Seismic Debris Flow Modelling Using Flo-2D; Case Study of Yingxiu, Sichuan Pronvince, China
}

\author{
Mamodu Adegbe ${ }^{1}$, Dinand Alkema ${ }^{2}$, Victor G. Jetten ${ }^{2}$, Ako Thomas Agbor ${ }^{1}$, Idris Nda Abdullahi ${ }^{1}$, Onoduku \\ Usman Shehu ${ }^{1} \&$ Abraham Stephen Unubi ${ }^{1}$ \\ ${ }^{1}$ Department of Geology, Federal University of Technology, Minna, Niger state, Nigeria \\ ${ }^{2}$ Department of earth system science analysis, ITC, University of Twente, Enschede, Netherlands \\ Correspondence: Mamodu Adegbe, Department of Geology, Federal University of Technology, Minna, Nigeria. \\ Tel: 234-703-049-6207. E-mail: adegbemamodu@futminna.edu.ng
}

Received: June 19, 2013 Accepted: July 31, 2013 Online Published: August 7, 2013

doi:10.5539/jgg.v5n3p101 URL: http://dx.doi.org/10.5539/jgg.v5n3p101

\begin{abstract}
In many parts of the world debris flows are one of the most dangerous of all mass wasting events. Mountainous areas with high slope instability, high seismic activities and extreme rainfall condition are the main triggering factors. The Monday, May 12, 2008, mega-earthquake of magnitude 8.0 that struck the Wenchuan area, Northwestern Sichuan province in China was catastrophic. This event, led to co-seismic landslides and subsequent rainfall induced debris flow in Yingxiu catchment on August $14^{\text {th }}, 2010$. The catchment has a very steep topography, an area of $5.35 \mathrm{~km}^{2}$ and a channel length of $3.55 \mathrm{~km}$. The aim of this research is to model the post seismic debris flow, Parameterize and calibrate the event. Two main initiation zones were identified based on susceptibility assessed from geomorhological mapping and formed the bases for input in the FLO-2D model. $161,350 \mathrm{~m}^{3}(64.54 \%)$ of the debris flow volume was modeled with FLO-2D in a manner consistent within the limit of the data available. FLO-2D model do not incorporate entrainment of materials in the transport zone. Thus, limitation to the production of the total deposits volume on the debris flow fan. The model was parameterized and the result shows that, Sediment concentration and the coefficient of friction were the two main parameters that affected the velocity of debris flow, area of inundation and the impact force respectively. Finally, the debris flow was calibrated using a back analysis of the debris flow event of 2010.
\end{abstract}

Keywords: Seismic, debris flow, FLO-2D model, parameterize, calibration

\section{Introduction}

In many parts of the world debris flows are one of the most dangerous of all mass wasting events. Mountainous areas with high slope instability, high seismic activities and extreme rainfall condition are the main triggering factors (Huang \& Li, 2008). Debris flows are also referred to as mudslides, mudflows, debris avalanches, or hyperconcentrated flow (Kowalski, 2008). Debris flow is a common type of landslides that occur generally during intense rainfall on water saturated soil. They can occur suddenly and inundate entire towns in a matter of minutes. Also, the mass can travel long distances over fairly gentle slopes damaging structures and many other elements that lie in their paths (Kowalski, 2008). Different elements at risk such as people, building and infrastructures, whether in urban or rural environments, are either directly or indirectly affected by the occurrence of these events, disturbing their economy, development and sustainability.

The Monday, May 12, 2008, mega-earthquake of magnitude 8.0 that struck the Wenchuan area, Northwestern Sichuan province in China was catastrophic Tang et al. (2011). This high intensive earthquake disturbs the slope bedrock and creates an abundance of loose landslide debris on the slopes and gullies and maybe reactivated old landslides. This affects the stability of these slopes for a long period of time. The debris later serves as source material for rainfall induced debris flows as reported by Lin et al. (2006). The Yingxiu town was devastated by large debris flow in August 14, 2010 after rainfall events of short duration. The debris flows from the catchment produced a debris dam which then changed the course of the Minjiang River and resulted in the flooding of the Yinxiu town, including the newly reconstructed settlement. This catastrophic flood event claimed the lives of 56 people. More than 5,500 residents at high risk were forced to evacuate (Tang et al., 2011). 
The Debris flows were triggered by a combination of three essential factors: sufficient available loose material, surface runoff, and steepness of the drainage channels on the slopes Tang et al. (2011). The Yingxiu catchment is located on the left bank of the Minjiang River and has a catchment area of $5.35 \mathrm{~km} 2$ and a channel length of 3.55 $\mathrm{km}$. The upslope elevation of the gully is more than $1,700 \mathrm{~m}$ above sea level and the gully mouth is at $880 \mathrm{~m}$ above sea level. The highest part of the debris flow source area is at $2,168 \mathrm{~m}$ above sea level. The Yingxiu-Beichuan fault just runs through the catchment. This makes the study area an active seismic spot and interesting for post seismic debris flow studies. The focal mechanism of the earthquake was successive massive rock fracturing $15 \mathrm{~km}$ in depth at the lower part of the catchment was reported by Tang et al. (2011).

Seismic analysis confirms that the major shock occurred on the Beichuan-Yingxiu Fault and that aftershocks rapidly extended in a straight Northeast-Southeast direction. Due to the high seismic intensity of the earthquake, most of the large landslides moved at high speed and for considerable distances (Huang \& Li, 2008).

The Yingxiu debris flow was modeled using FLO-2D software. However, the model was parameterized and calibrated. It can be anticipated that post-seismic geohazard, particularly for debris flows, will continue for 5-10 years and even for as long as 20 years (Cui et al., 2009). It should be noted that identification of the areas that might be inundated by future debris flows and estimates of flow volume/area extent are required to quantify debris flow hazard.

For physical planning, reconstruction, prevention, debris flow mitigation, risk assessment and risk management reasons, there is the need for a detailed debris flow modeling, parameterization and calibration of the post seismic debris flow in the Yingxiu catchment. This will help in gaining a better understanding of the processes and debris flow propagation. The accurate prediction of run-out distances and velocities can reduce losses by providing a means to delineate hazard areas, to estimate hazard intensity for input into risk studies and to provide parameters for the design of protective measures (Cesca \& D'Agostino, 2006).

Debris flows are increasingly a concern in China; as a result, different studies have been conducted since the event of the Wenchuan 8.0 magnitude (Richter scale) Earthquake disaster which led to other induced secondary geohazards like Debris flow. Most of the researches done were concentrated on the earthquakes, Landslide, damage estimations and building evaluation (Cui et al., 2009) with a little or nothing documented on the debris flow modeling. Hence, this research was targeted at attempting to model the debris flows in the catchment so as to generate past and may be predict future debris flow scenarios. The estimation of the dynamic characteristics of debris flows is in fact needed by administrators, decision makers, planners and practitioners who have to protect the life, the property and the economic activities of people who live in debris flows prone areas (Petrascheck \& Kienholz, 2003).

Debris flows are very viscous, hyperconcentrated sediment flows and are also referred to as mud flows. Mudflows are non-homogeneous, non-Newtonian, transient flood events whose fluid properties change significantly as they flow down steep watershed channels or across alluvial fans. Mudflow behavior is a function of the fluid matrix properties, channel geometry, slope and roughness. The fluid matrix consists of water and fine sediments. At sufficiently high concentrations, the fine sediments alter the properties of the fluid including density, viscosity and yield stress (FLO-2D manual, 2007). In addition, the digital elevation model (DEM) is a crucial input to the Model and will determine to a large extent, where the flow will occur and in how far it will be confined to natural or artificial channel that are found in the landscape. Therefore, the quality of the DEM is important in the debris flow mechanics (behavior). Spatial relations and distribution on how debris flow behave in response to a triggering factor have been analyzed by many researchers such as Tang et al. (2011), Chigira et al. (2003), Keefer (1984), Khazai and Sitar (2004), in which they have stated out that debris flow are related to geo-environmental precursors but even more to seismic parameters such as fault type, displacement, earthquake depth and magnitude.

Modeling debris flow as a complete phenomenon is complicated. The present research is focused on only the initiation conditions that are causative to the debris flow and attempt to model the debris flow event. There are different factors that determine the reach of Debris flows and the associated hazards. The initial mass, the friction component during the flow and the amount of material entrained or picked up during the flow (scouring).

Modeling plays an important role in debris flow propagation by enhancing knowledge and understanding (Moradkhami \& Sorooshian, 2009). In debris flow modeling, several considerations have to be addressed. While there are many models, they differ essentially in structure and treatment of the hydrological and hydraulic processes as well as the assumptions they hold. Abulohom et al. (2001) emphasized that, there is no universal model and as such, the data availability, type of hydrologic quantity to be modeled, scale of operation, accuracy 
required, availability, computing facilities, political and economic considerations are important in the choice of model for a particular work.

Researchers overtime have approach debris flow initiation modeling in several ways. Aleotti (2004) uses threshold based warning system for debris flow prediction. The method results in identifying rainfall events, which are potentially capable of initiating debris flow. Glade et al. (2000) uses antecedent rainfall daily rainfall model to calculate the regional landslides triggering rainfall thresholds in this model. Debris flow has also been modeled using the RAMMS (Rapid mass movements) dynamic numerical software package which was originally designed to model snow avalanche Christen et al. (2010). But has been applied in the past to model other types of mass movements like lahars (Quan Luna, 2007) and debris flows (Cesca \& D'Agostino, 2006); (Kowalski, 2008). The dynamic RAMMS model is based on the Voellmy-Salm model which assumes that the total basal friction of the flow can be categorized into two, namely: a velocity independent dry-coulomb friction coefficient $(\mu)$ and a velocity dependent turbulent coefficient $(\xi)$.

FLO-2D model was chosen for this research because of the following reasons; firstly, it incorporates rainfall and digital elevation parameter into the model similar to other model mentioned in this work. However, it also incorporates multiple initiation areas unlike the other ones. Secondly, it enables the researcher to model debris flow with the initial volume of materials without entrainment. This is a limitation of the model. However, it enables the researcher better understands the propagation processes without the interferences of other external materials.

\section{Geology and Geography}

The Yingxiu catchment is located in the Sichuan province, (Figure 1) Southwest China. The catchment has an area of $5.35 \mathrm{~km}^{2}$ with a length of $3.55 \mathrm{~km}$. It is the epicentre and one of the single worst hit areas of the 2008 Sichuan Earthquake. $80 \%$ of the town was destroyed by the earthquake. (Tang et al., 2011).

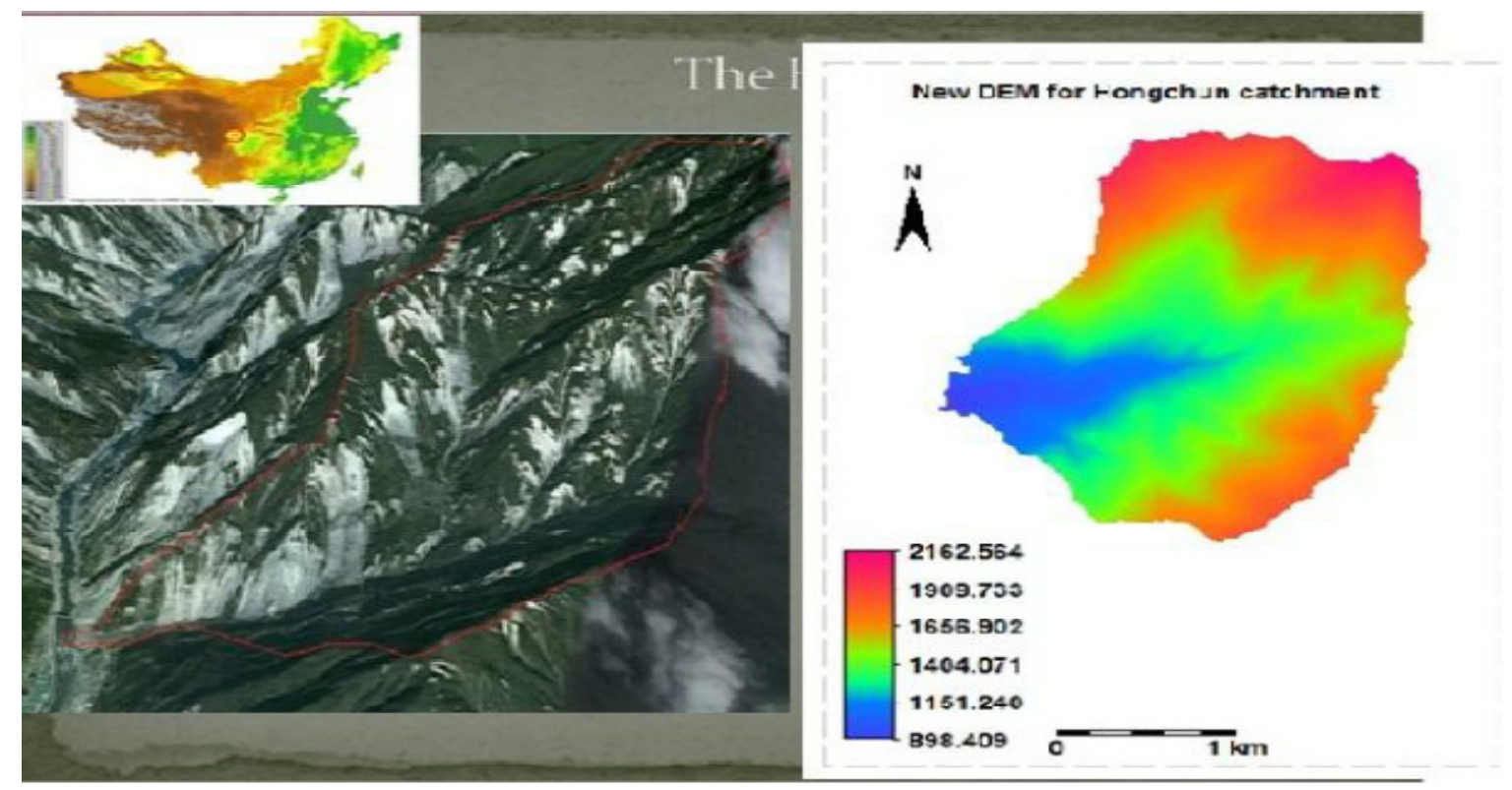

Figure 1. Yingxiu catchment and digital elevation model of the study area

The study area is underlain by granitic rocks (Figure 2) and was mapped during the fieldwork. All bedrock is deeply fractured and highly weathered, and covered with a layer of weathered material. Joints are well developed in the more competent lithologies (Figure 2).

When combined with active faulting and bedding, produces many potential failure surfaces in the rock slopes. The geological main structure and the strike of the rock strata in the study area show a NE-SW orientation .Tang et al. (2011) reported that, the Yingxiu-Beichuan faults ruptured during the Wenchuan earthquake runs through the study area. 

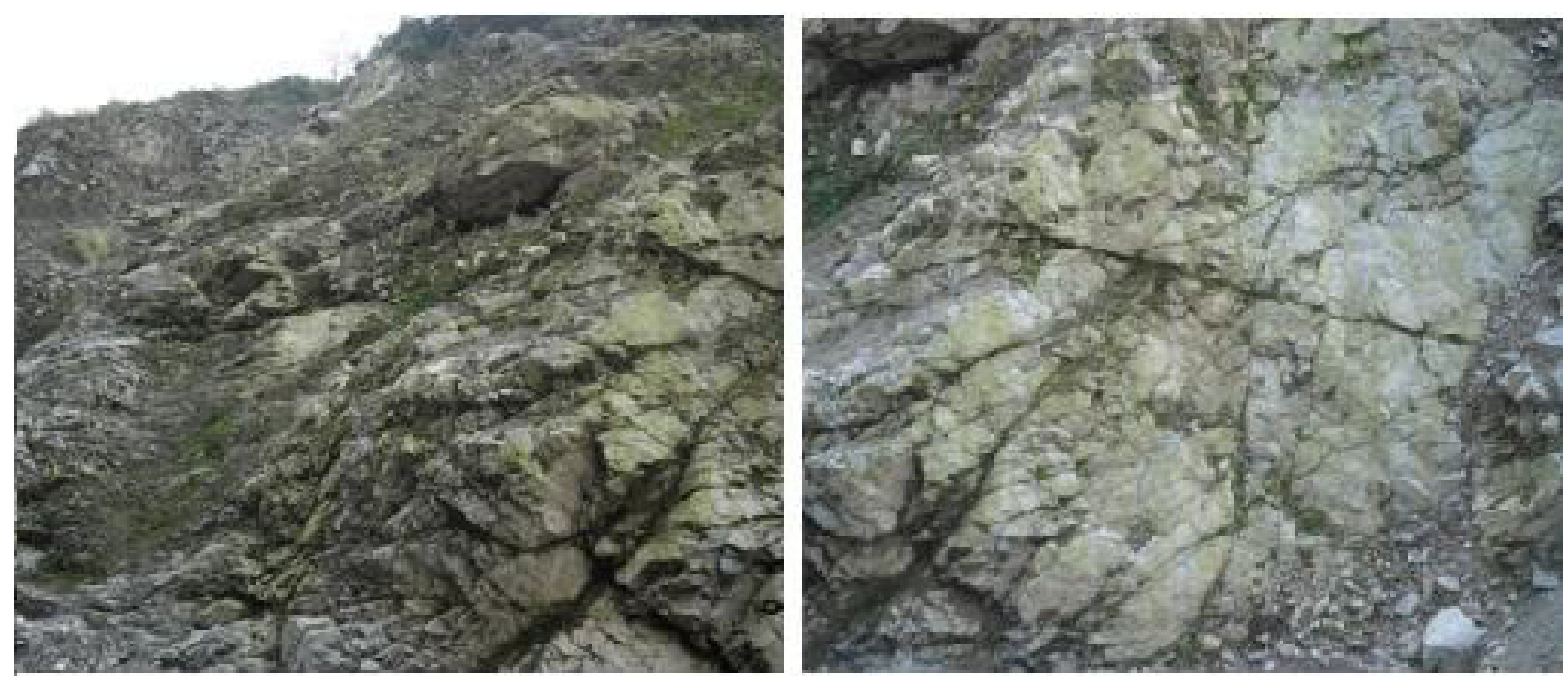

Figure 2. Photograph showing exposed massive granitic rocks in the Yingxiu catchment with deep fractures (source: Fieldwork, 2011)

The study area is situated in the typical humid subtropical, monsoon climate zone with an annual average temperature of $12.9^{\circ} \mathrm{C}$. The annual average precipitation over a period of 30 years is $1,253 \mathrm{~mm}$, with a highest recorded annual precipitation of $1,688 \mathrm{~mm}$ in 1964. The maximum recorded rainfall intensity was $269.8 \mathrm{~mm} /$ day in 1964. (Tang et al., 2011) .The rainfall is largely concentrated in the period from June to September. On average, $70 \%$ of the annual precipitation falls during this period. A total of accumulated rainfall of $162.1 \mathrm{~mm}$ in 33 hour was recorded from 17:00 P.M. on 12 August, until 02:00 A.M. on 14 August. The rainfall intensity that induced the debris flows occurred between 02:00 and 03:00 A.M.; $16.4 \mathrm{~mm} / \mathrm{h}$ was recorded during that time period (Tang et al., 2011). The intensity of rainfall necessary to initiate debris flows in the Yingxiu catchment is poorly known and also was not the main interest of this research. Previous studies in the Longmenshan area Tan and Hen (1992) have reported rainfall that initiates debris flows to have intensities greater than $30-50 \mathrm{~mm} / \mathrm{h}$ with a total rainfall of at least $80-100 \mathrm{~mm}$. Lan et al. (2003) examined rainfall amount $110 \mathrm{~mm} /$ day as the rainfall thresholds for the occurrence of past landslide events in the Xiaojiang watershed, southwestern China. Comparing the characteristics of the triggering rainfall with these thresholds reported for China in the literature, the August 14 event indicated that post-earthquake debris flows in the Yingxiu catchment can be triggered by longer duration, lower intensity rainfall was reported by Tang et al. (2011). The main river in the study area, the Minjiang River, originates in the northwestern mountainous area. Its annual mean discharge is $452 \mathrm{~m}^{3} / \mathrm{s}$ and peak stream discharges averaged $2,790 \mathrm{~m}^{3} / \mathrm{s}$ in 1958 . The river in the Yingxiu catchment has two main tributaries at the upper part of the catchment.

The Yingxiu catchment has a very steep slope and rugged terrain (Figure 3). The highest point on the catchment is over $2000 \mathrm{~m}$ above sea level high while the lowest point at the valley floor is above $800 \mathrm{~m}$ above sea level. Topography has a uniform vegetation cover except for area where the landslides have distorted the vegetation. 


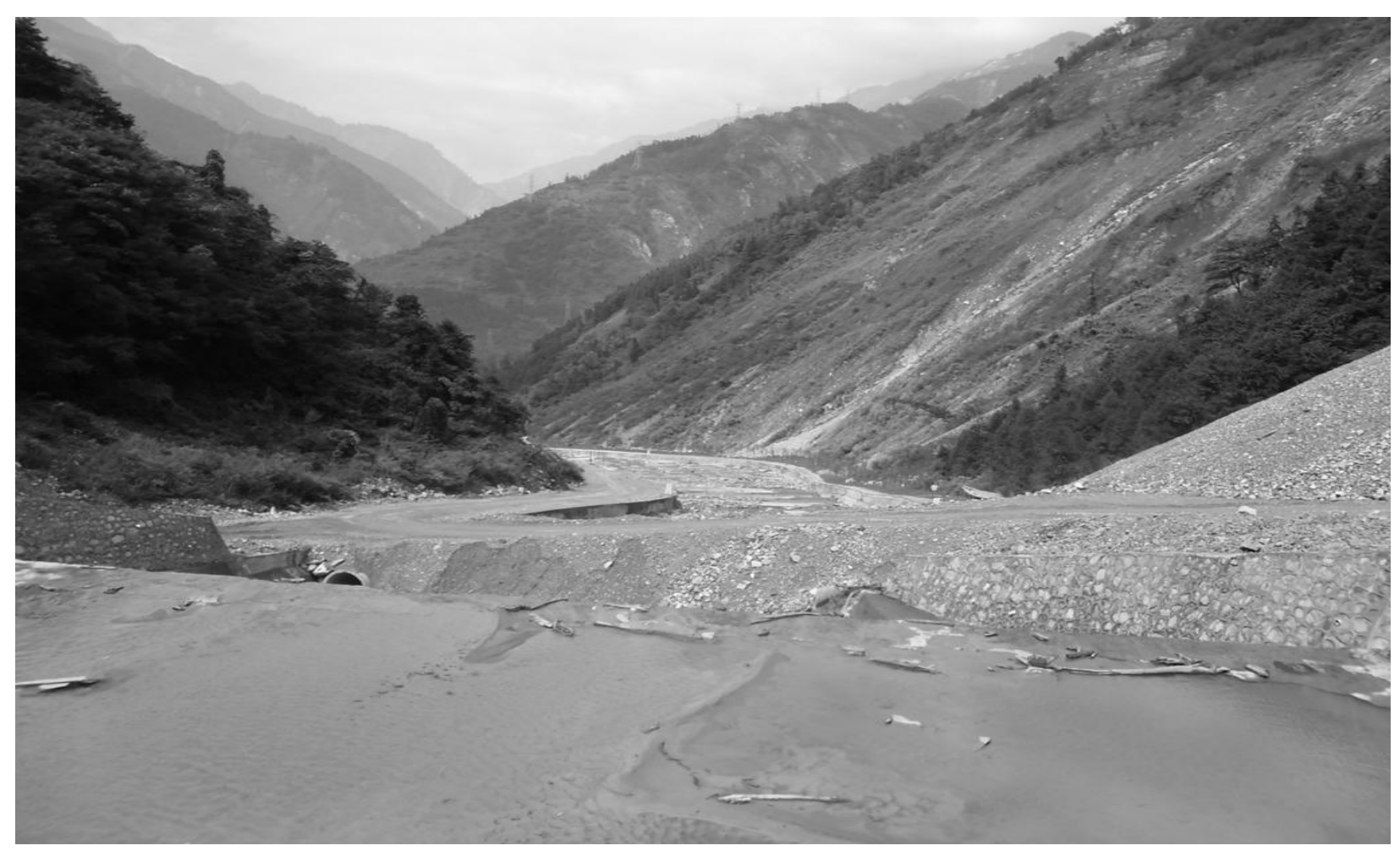

Figure 3. Photograph showing rugged topography and uniform vegetation in the catchment

(source: Fieldwork, 2011)

\section{Materials and Method}

The method of investigation of this study consisted of fieldwork, laboratory work and modeling with FLO-2D.

\subsection{Fieldwork}

An intensive fieldwork was carried out for two weeks at Yingxiu, China. During the period, information on the co-seismic landslides were mapped and characterized. Also, local knowledge was elicited through interview.

Geological mapping of the area was carried out to:

(1) Determine the geological and environmental factors that must have caused the landslides. Attention was paid on the rock type, fracture and degree of slope and human activities along the slope toe of the hill.

(2) Collection of soil samples from the major landslides site for the determination of physical properties such saturated hydraulic conductivity (Ksat), porosity, bulk density, field capacity and moisture content.

(3) Geomorphological determination of initiation zone(s).

\subsection{Laboratory Work}

Post field work involved one week intensive laboratory analysis of soil samples to determine soil physical parameters to use in the FLO-2D model. Saturated hydraulic conductivity (Ksat), porosity, initial moisture content, field capacity and bulk density were determined as outlined below. The 24 soil samples taken from the field were analyzed in the State Key Laboratory of Geohazard Prevention and Geoenvironmental Protection of the Chengdu University of Technology.

The 24 soil samples were taken from the landslide scar, bodies and insitu based on accessibility in the catchment. They were inturn, put in nylon filters. The weight $\mathbf{W} 1$ of each sample was determined using weighing scale. The samples were then put in water for 24 hours to saturate. However, it was observed during the saturation of the soil samples that within 5 minutes, the water was already seen to start appearing on the surface. This may be due to the loosed nature of the soil and the stoniness observed in the field. This make the soil very porous and with a very high permeability. The saturated weight $\mathbf{W} \mathbf{2}$ was taken and recorded. The saturated weight was then put in the test set-up to create constant head. The constant head of $1 \mathrm{~cm}$ was maintain throughout the laboratory analysis this was because it allows the effective monitoring of the water movement through the soil samples, giving the 
nature of the soil described earlier. Higher constant head tends to increase, the flow of the water through the soil, maybe as the pressure of the water increase with height. The constant head $\mathrm{dH}$ was measured, the amount of percolated water per constant time, e.g. $5 \mathrm{~min}$ or $10 \mathrm{~min}$ was measured. The percolated water was observed carefully and recorded after every 5 minutes. This was stopped when the reading becomes constant. The rings were then put on the rack for 24 hours to let water leak out. The caps were removed and sample weight W3 was taken. We put the rings in an oven at 105 degree centigrade for 24 hour (in a tray). After that, weight W4 was taken.

The soil sample was removed and the rings were cleaned, then weight $\mathbf{W 5}$ was taken after the cleaning.

In order to calculate the various parameters mentioned the soil physical parameters mentioned earlier, the following procedures were followed.

To calculate the various parameters:

Calculate volume of the ring $(\mathrm{Lx} \mathrm{A})$ in $\mathrm{ml}\left(=100 \mathrm{~cm}^{3}=100 \mathrm{ml}\right)$.

(To convert differences in weight due to changes in soil water content, consider that 1 gram of water $=1 \mathrm{ml}$ of water).

Porosity: Pore space (volume) divided by total sample volume.

Pore volume $=(\mathrm{W} 2-\mathrm{W} 5)-(\mathrm{W} 4-\mathrm{W} 5)$ (express result in $\mathrm{ml})$.

Porosity $=100 \% \mathrm{x}$ Pore volume $/$ Ring volume.

Field moisture content: Amount of water in the soil at the moment of sampling.

Field moisture volume $=(\mathrm{W} 1-\mathrm{W} 5)-(\mathrm{W} 4-\mathrm{W} 5)(\mathrm{ml})$.

Field moisture content $=100 \% \times$ Field moisture volume $/$ Ring volume .

Field capacity: Amount of water in the soil after the soil has been drained by gravity forces $(\approx$ soil dependent).

Field capacity volume $=(\mathrm{W} 3-\mathrm{W} 5)-(\mathrm{W} 4-\mathrm{W} 5)(\mathrm{ml})$.

Field capacity $=100 \% \mathrm{x}$ Field capacity volume / Ring volume.

Bulk density $=($ W4-W5) / Ring volume.

\subsection{Modelling with Flo-2D}

FLO-2D being a lumped hydrology and hydraulic model was used in modeling the Yingxiu debris flow. It is also, a flood-routing model, which uses a dynamic-wave momentum equation and a finite-difference routing scheme. Its formulation is based on the depth-averaged open channel flow equations of continuity and momentum for unsteady conditions developed on an Eulerian framework. The adopted numerical analysis technique is a non-linear explicit difference method. (Cesca \& D'Agostino, 2006).

The general constitutive fluid equations include the continuity equation, and the equation of motion (dynamic wave momentum equation): FLO-2D assumes the following constitutive equation (quadratic model):

$$
\tau=\tau_{c}+\mu_{N}(d u / d y)+C(d u / d y)^{2}
$$

Where $\tau$ is the total shear stress $(\mathrm{Pa}), \tau \mathrm{c}$ the yield stress $(\mathrm{Pa}), \mu_{\mathrm{N}}$ the dynamic viscosity $(\mathrm{Pa} \mathrm{s}), \mathrm{du} / \mathrm{dy}$ the shear rate $\left(\mathrm{s}^{-1}\right)$ and $\mathrm{C}$ is the inertial stress coefficient. Unless a rheological analysis of the mudflow site materials is available, the following empirical relationships can be used to compute viscosity and yield stress.

$$
\tau_{y}=\alpha_{2} e^{\beta_{2} C_{v}} \text { and } \eta=\alpha_{1} e^{\beta_{1} C_{v}}
$$

Where $\alpha \mathrm{i}$ and $\beta \mathrm{i}$ are empirical coefficient defined by laboratory experiment (O`Brien et al., 1993).

The viscosity (poises) and yield stress $\left(\right.$ dynes $\left./ \mathrm{cm}^{2}\right)$ are shown to be function of the volumetric sediment concentration.

For purpose of this research, the following procedures were followed. First, a database containing all the input data was built. The $10 \mathrm{~m}$ DEM (asc) was imported into the model as ASCII grid files. The $10 \mathrm{~m}$ DEM prior to being used in the FLO-2D was converted from Arcgis shape file (raster) to ASCII grid files. A fill sink operation was also carried out on the $10 \mathrm{~m}$ DEM (asc). The grid size was defined as 30 , so as to manage effectively the 
model runs time. However, selecting smaller grid size does not necessarily increase the model resolution but increases the computational time (FLO-2D manual, 2007).

The model requires that each grid element be assigned a representative elevation this is done by interpolation, because a set of DEM points may be randomly distributed in the flow domain and some grid elements may have many points while other might not. However, the default interpolation technique was used in this research. For this research, the initiation areas represent the unstable area and were determined from the geomorphological mapping of the catchment. Two main areas of the catchment top were mapped as the source area contrary to Tang 2011 who identifies only one source area for the same catchment. These areas also tally with two big landslides scarp as mapped in the field. Also they were evidences of tree falling forward in those areas signifying instability. The falling of the trees or leaning forward was not due to the response of the tree towards light absorption because the stems were not folded or bended.

A constant sediment concentration 0.5 by volume was used. This was mainly due to lack sediment concentration data for the catchment. In view of this, hyperconcentrated sediments flow parameters, such as, the viscosity and yield stress were determined from the literature (FLO-2D manual, 2007). The sediment specific gravity was set at 2.65 (default throughout the research) while the $\mathrm{K}=$ laminar flow resistance was set at 24 . This is in- line with the guideline in the FLO-2D manual.

\section{Results and Discussion}

\subsection{Fieldwork}

The fieldwork revealed through the landslides inventory mapped that the co-seismic landslide body in the Yingxiu catchment were the source of the debris for the subsequent rainfall induced debris flow that struck the town. This was also confirmed from the interview segment of the fieldwork that prior to the May 12th, 2008 Earthquake, there were no record of landslides in the catchment. A total of 41 landslides were observed in the catchment. The scarp and the body of the landslides were also observed (Figure 4).

Other sources of debris include channel floor erosion and weathered rock/soil on steeped slope with very high fracture, thus making them unstable. However, this was also observed during the fieldwork. The topography of the catchment played a key role in the remobilization of debris in the catchment as it is very steep, with highest point about $2100 \mathrm{~m}$ above sea level. The materials from the slide were made up of large to small debris of granitic rocks as shown by field relation. The catchment was characterized by numerous faults which may have been developed as a result of the earthquake that struck the catchment. The Yingxiu-Beichuan fault runs through the catchment and as a result, made the catchment more vulnerable to landslide activities. This event, led to the availability of debris (landslide bodies) which, were ultimately remobilized by the rainfall induced debris flow.

The three days antecedent rainfall may have saturated the landslides bodies, under such conditions, the material of the landslide bodies will lose cohesion and be readily moved with steep slope that characterize the catchment.

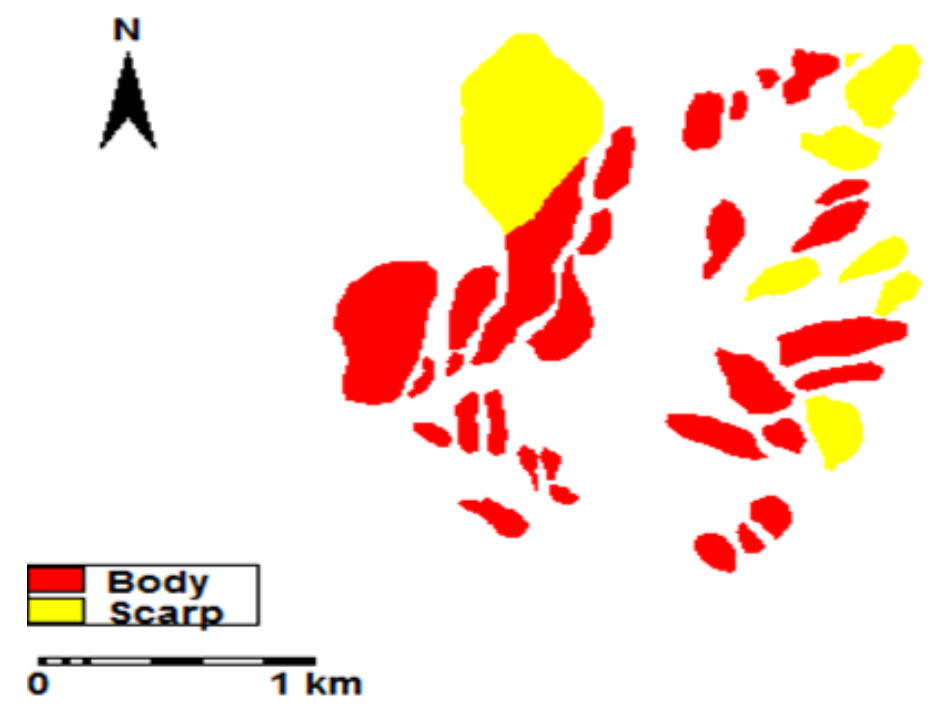

Figure 4. Landslides scarp and body as mapped in the field 
After the debris flow events of 2010, Tang (2011) identified one main source area, contrary to the two main initiation zones identified during this study (Figure 5). Tang (2011) further studied the occurrence of debris flows in the Yingxiu catchment and one of the conclusions of his work was outlining the area that was most susceptible to future debris flow initiations.

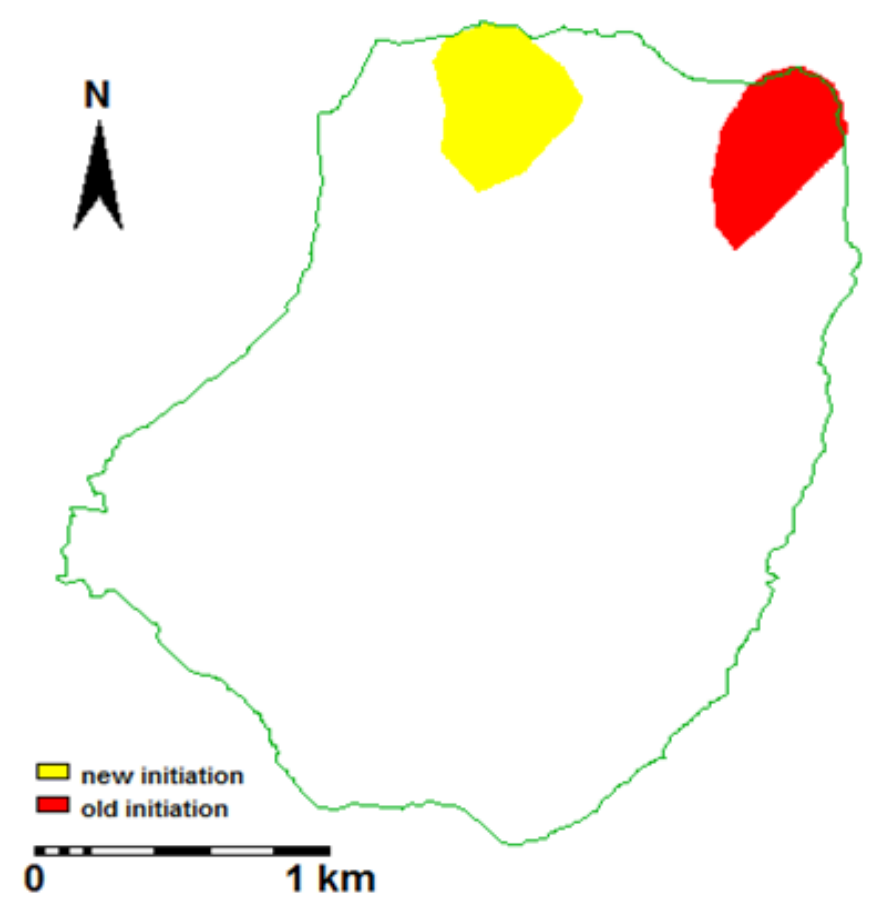

Figure 5. diagram showing debris flow initiation areas of the landslides

These two mapped initiation zones were used in the FLO-2D model as they represent areas with very high susceptibility in the catchment and thus are the unstable areas in the catchment. These two identified areas of debris flow initiation (Figure 5) were marked as the most susceptible to future debris flow initiations based on field observations and geomorphological analysis. These susceptible areas are located at the top of the catchment. The location of check dams along these parts of the catchment further confirms the field observations and geomorphological analysis of the susceptible areas of future debris flow events and shows the most activity.

With respect to this information on susceptibility, the two initiation zones were defined and used in the FLO-2D model. However, volume of the initiations was not known.

The fieldwork revealed that there are no current human activities like farming or housing within the catchment. However, this was not the case prior to the earthquake and subsequent landslide that hit the catchment. It was confirmed during the interview that they used to be farming activities mainly for consumption on a small scale. The earthquake and subsequent landslides made the catchment to classified as a high risk zone and the government issued a stem warning that the farming activities in the catchment be suspended for safety reasons. And this was strictly adhered to the farmers. The relationship between human activities and the debris flow event was not the core of this research. However, literature has shown that human activities may led to slope instability mostly as the toe of the hills a constantly tilled during farming activities thereby creating the recipe for instability.

\subsection{Laboratory Result}

A summary of the statistics of measure of central tendency and dispersion is presented on Table 1. The soil physical properties assessed from the soil samples in the two laboratories are Ksat, porosity, field moisture content, bulk density and initial moisture. 
Table 1. Summary statistics of soil physical properties

\begin{tabular}{lllll}
\hline Physical properties & Mean & SD & Median & $\mathrm{n}$ \\
\hline Bulk density $\mathrm{g} / \mathrm{cm}^{3}$ & 1.42 & 0.24 & 1.36 & 24 \\
Field capacity & 0.35 & 0.09 & 0.36 & 24 \\
Moisture cont & 0.24 & 0.03 & 0.24 & 24 \\
Ksat & 0.66 & 0.11 & 0.64 & 24 \\
Porosity & 49.25 & 7 & 49 & 24 \\
\hline
\end{tabular}

The result of the 24 soil samples revealed that the saturated hydraulic conductivity, Ksat and the porosity for the catchment is quiet high. This may have facilitated rapid infiltration of the rain water into the landslides bodies, thus saturating the soil. Under this condition of saturation, coupled with numerous fault and the steep slope, the materials of the landslides bodies (debris) failed and where remobilized as debris flow. This debris flow move downward into the channel bed and entrained other materials of the stream bed before deposition on the debris flow fan.

The box plots of the Ksat, bulk density, porosity and moisture content were plotted against the texture respectively (Figures 6-9). The result reveals that the each of the soil parameters determined did not vary in each of the classes because the box plots for each of the class overlapped significantly with the texture.

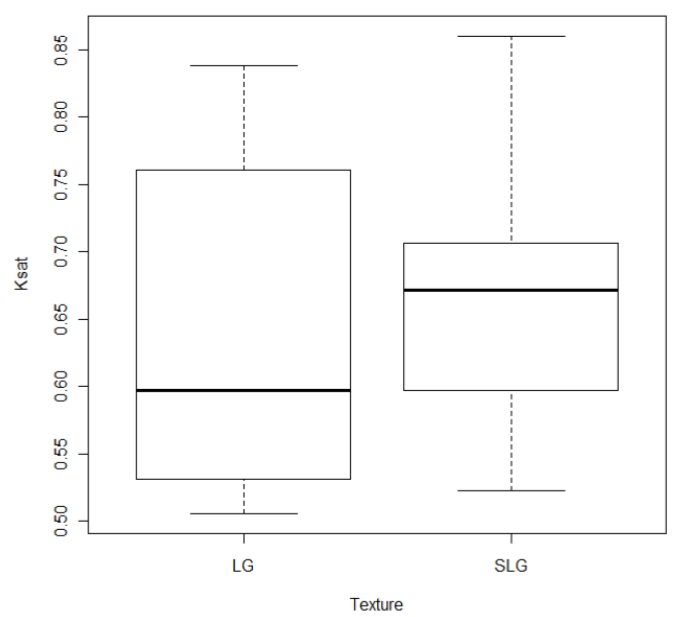

Figure 6. Ksat by texture class

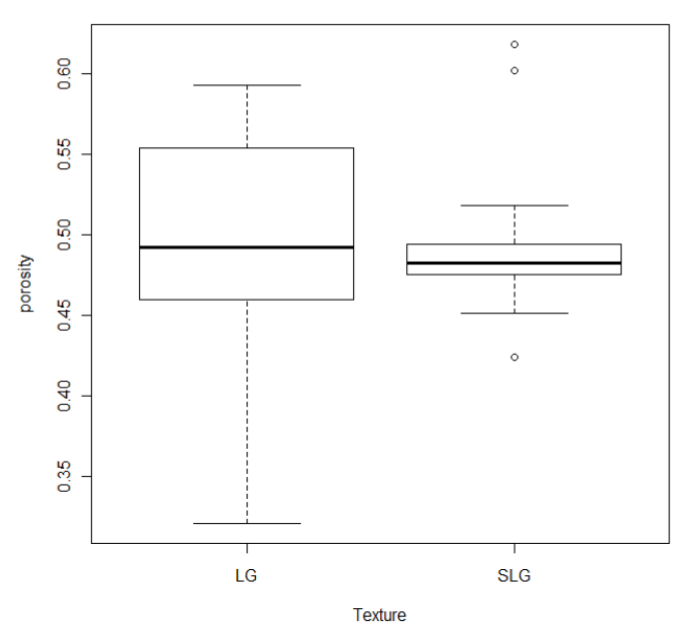

Figure 8 . Porosity by texture class

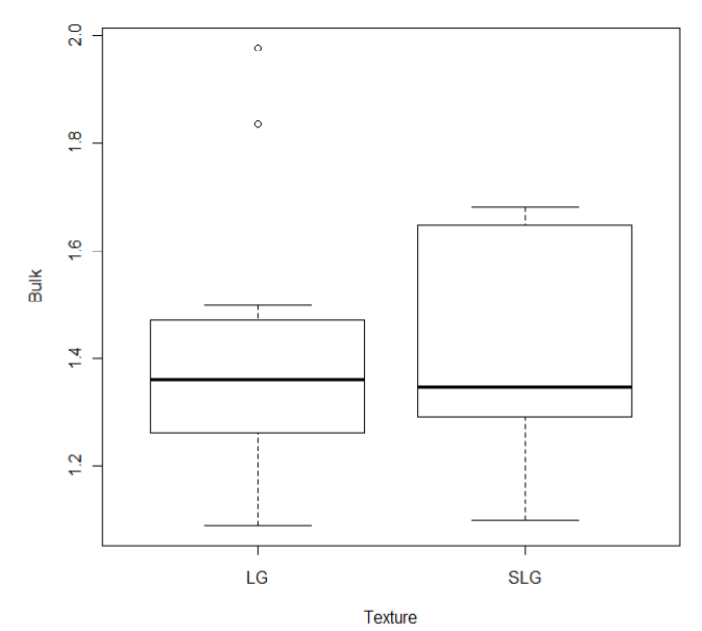

Figure 7. Box plot of Bulk density by texture class

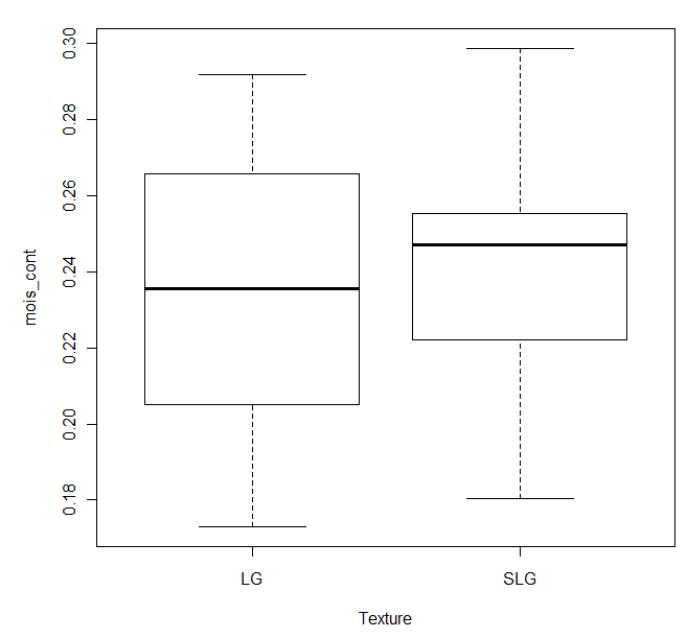

Figure 9. Moisture content by texture 


\subsection{Flo-2d Result}

The debris flow result shows the maximum flow velocity of $2.8 \mathrm{~m} / \mathrm{s}$ (Figure 10), maximum depth of $22.3 \mathrm{~m}$, (Figure 11) and the impact force of $4,559.6 \mathrm{~N} / \mathrm{m}^{2}$ (Figure 12) area of inundation of the is $955000 \mathrm{~m}^{2}$.

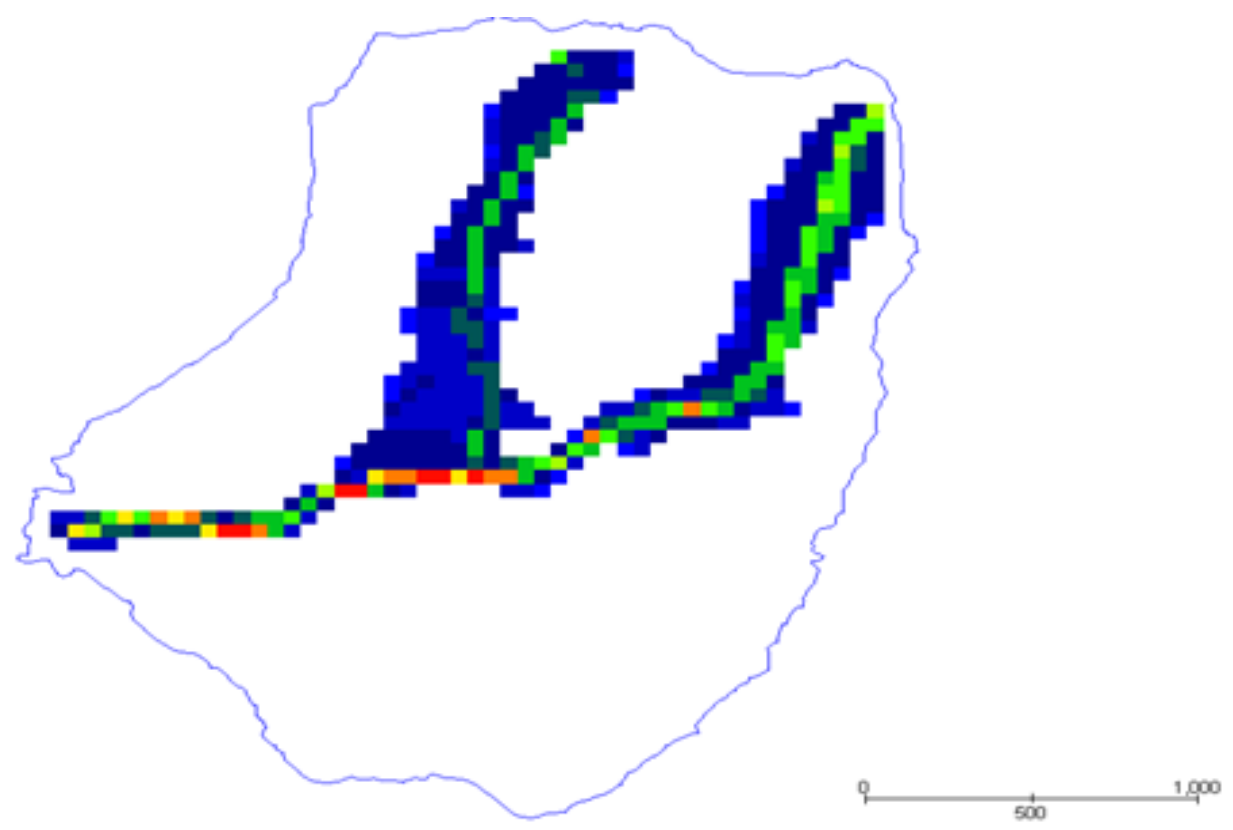

Figure 10. Debris flow grid maximum velocity

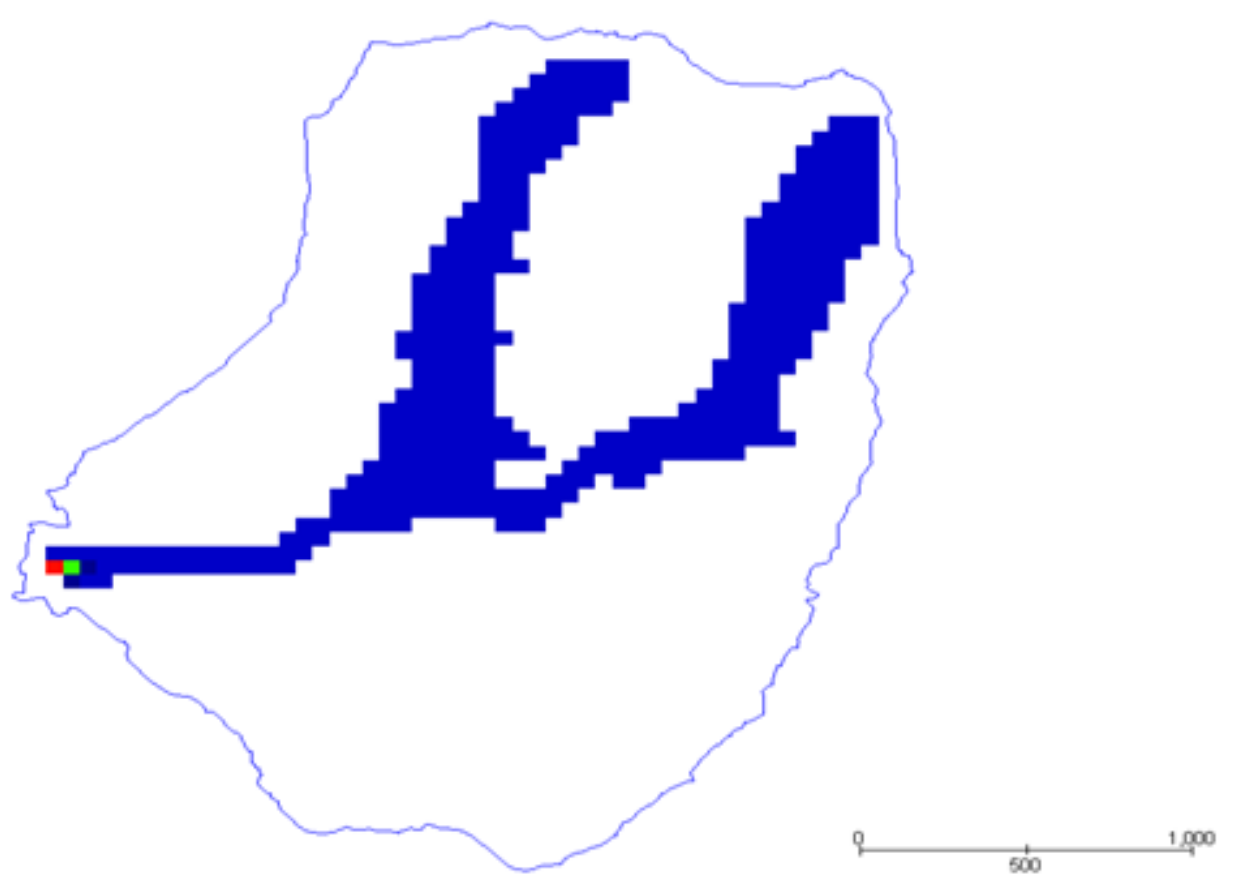

Figure 11. Debris flow grid maximum depth 


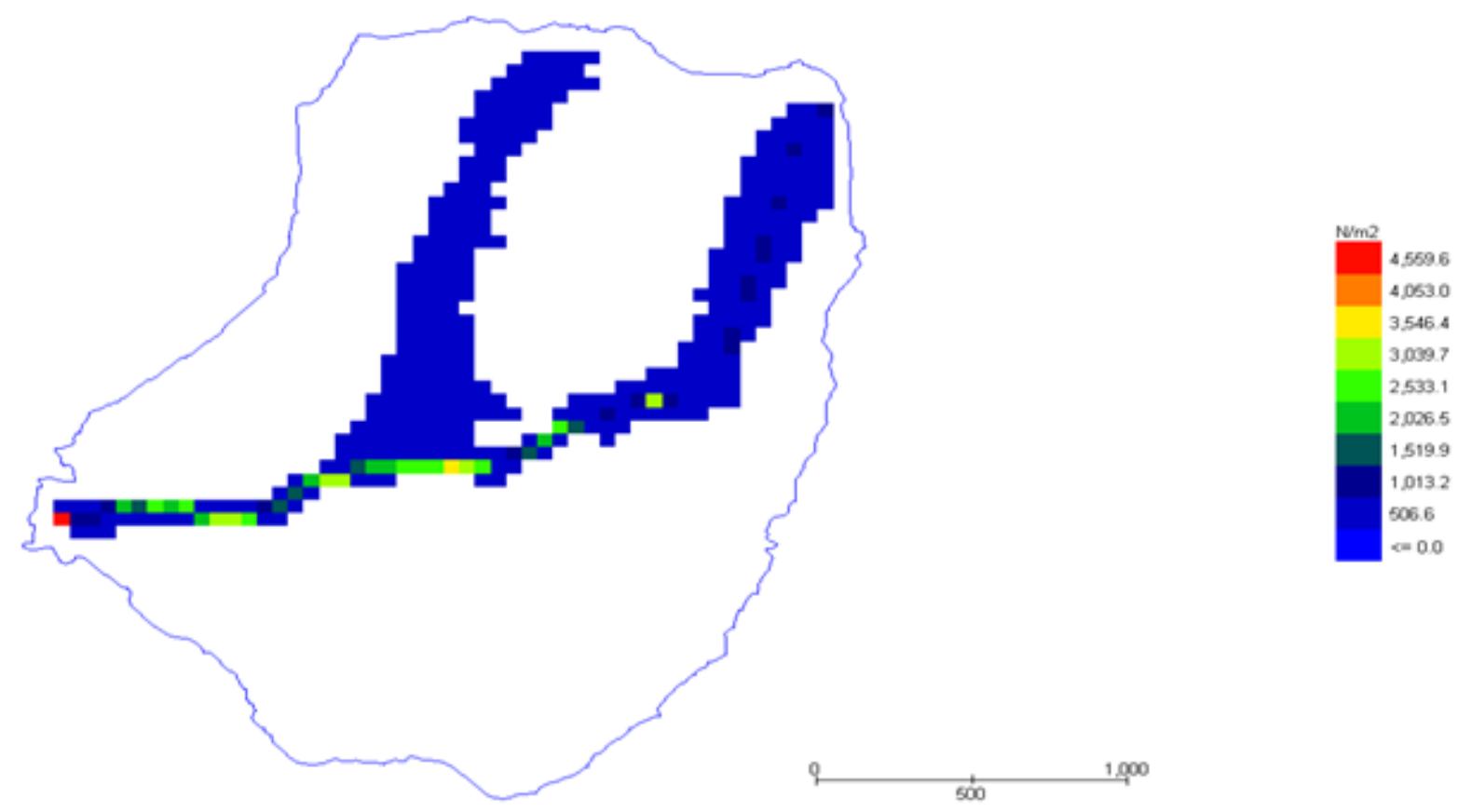

Figure 12. Debris flow grid impact force

The result shows that the velocity of the debris flow varies across the catchment (Figure 10). This may be partly due to the steep nature of the terrain which may contribute to the downward movement of the debris flow. Besides, this is may also be partly due to the volume of materials entrained along as the debris moves and the basal friction component of the flow at various point. They velocity is small at initiation points usually at the top of the catchment. At that point, the debris materials have not gained enough kinetic energy to flow due to inertial force that tends to restrict the flow of movement. The velocity becomes higher at the confluence of flows in the channel due to narrowing of the channel. However, the flow depth remains fairly constant but became higher at the mouth of the debris flow fan where all the debris flow materials tends to accumulate and thus build up a debris dam.

The impact force at the initiation point is low this may be due to the fact that the debris flow has not entrained materials so much to affect the impact force (Figure 12). The impact force changes as the debris moves through the channel due to channel narrowing. Narrowing of the catchment channel as seen during the fieldwork may be responsible for the high impact force around the confluence of the catchment. Also at this point, the debris has entrained other materials along its path and equip with large mass, thus resulting in high impact force.

\subsection{Parameterization (Sensitivity Analysis)}

\subsubsection{Sensitivity to Sediment Concentration}

A sensitivity analysis quantifies the variation in a model output due to variations in the model inputs. It shows how sensitive the output of the model is to change in the input and gives an indication which inputs parameter weighs more on the model. The sensitivity analysis was carried out on four inputs parameters. These parameters are: Sediment concentration, viscosity (viscosity coefficient and exponent), yield stress (yield stress coefficient and exponent) and manning's $n$ (friction coefficient).

However, the sediment specific gravity and laminar flow resistance "k" were kept constant at 2.65 and 24 respectively throughout this research.

Each single input parameter was increased or decreased by certain literature value, while the other input parameters were kept constant in order not to affect the sensitivity of the parameter being tested.

Sediment concentration is a basic important factor when analyzing debris flow simulations. Most debris flow studies require the estimation of the sediment concentration by volume since this is very important in describing the magnitude of an event. It is also important to note that the sediment concentration determines the classification of flows into water flood, mud flood, debris flows and landsides.

For this reasons, the sediment concentration by volume ranging from $0.3,0.4,0.5,0.6$ and 0.7 was tested while 
keeping other parameters constant see result in Table 2.

Table 2. Result of sensitivity analysis to sediment concentration

\begin{tabular}{llllll}
\hline Sediment concentration & 0.3 & 0.4 & 0.5 & 0.6 & 0.7 \\
\hline Total volume $\left(\mathrm{m}^{3}\right)$ & 150,100 & 155,491 & 161,353 & 167,749 & 174,754 \\
Max velocity $(\mathrm{m} / \mathrm{s})$ & 2.9 & 2.9 & 2.8 & 2.6 & 2.6 \\
Average depth $(\mathrm{m})$ & 10.1 & 11.0 & 11.2 & 11.3 & 11.4 \\
Average specific energy $(\mathrm{m})$ & 10.1 & 11.2 & 11.2 & 11.3 & 11.4 \\
Max impact force $\left(\mathrm{N} / \mathrm{m}^{2}\right)$ & 3,554 & 4,007 & 4,559 & 5,355 & 5,597 \\
Area of inundation $\left(\mathrm{m}^{2}\right)$ & 945000 & 947500 & 950000 & 955500 & 975000 \\
\hline
\end{tabular}

The results of the sensitivity analysis of the sediment concentration by volume are shown above (Table 2), it can be seen that an increase in the value of the concentration leads to an increase in the debris flow total volume, impact force which is a magnitude (intensity) factor. This is in agreement with the FLO-2D manual which state that the concentration is very important in describing the magnitude of an event. With increasing sediment concentration from 0.3 to 0.7 lead to an increase in the impact force from $3,554 \mathrm{~N} / \mathrm{m}^{2}$ to $5,597 \mathrm{~N} / \mathrm{m}^{2}$ respectively. However, the increase in concentration means increases the kinematic energy of the fluid matrix activities since the fluid will have gain more weight from the entrained sediment particles. The impact force tends to be higher at the confluence of the catchment where the two main sources of debris flow in the catchment converge from as a result of the combined effect at that point. The area of inundation also increase a little because they will be more sediment to be deposited along the channel, bank and at the debris flow fan.

With increase in concentration, the velocities at some point remain constant at $2.9 \mathrm{~m} / \mathrm{s}$ (Table 2), then drop to 2.8 $\mathrm{m} / \mathrm{s}$ when the concentration was 0.5 and remain constant again with further increase in concentration (Table 2). The reason why further increase in concentration, velocity generally decreases this is because the properties of the fluid matrix has change and become heavier with increasing concentration thereby decreasing the velocity. The debris flows velocities tend to be are higher mainly at the channel after the confluence (Figure 10) due to the narrowing of the channel at that point thereby increasing the fluid particle contact/collision leading to higher velocity. The debris flow depth and the specific energy vary slightly with increase in concentration.

\subsubsection{Sensitivity to Manning'S N (Coefficient of Friction)}

Debris flow behavior is a function of the fluid matrix properties, channel geometry, slope and roughness. All other parameter (viscosity, yield stress, sediment specific gravity, Laminar flow resistance "K") were held constant in including the sediment concentration (0.5) while testing the changes manning's $\mathrm{n}$ to volume/ areal extent, velocity, depth, specific energy and the impact force of the debris flow respectively.

The result of the sensitivity analysis to the coefficient of friction is shown in Table 3

Table 3. Result of sensitivity analysis to coefficient of friction

\begin{tabular}{lllll}
\hline Coefficient of friction & 0.005 & 0.04 & 0.15 & 0.250 \\
\hline Total volume $\left(\mathrm{m}^{3}\right)$ & 161,352 & 161,350 & 161,357 & 161,376 \\
Max velocity $(\mathrm{m} / \mathrm{s})$ & 2.6 & 1.8 & 1.1 & 0.8 \\
Average depth $(\mathrm{m})$ & 11.2 & 11.2 & 10.5 & 9.7 \\
Average specific energy $(\mathrm{m})$ & 11.2 & 11.2 & 10.5 & 9.7 \\
Max impact force $\left(\mathrm{N} / \mathrm{m}^{2}\right)$ & 4,058 & 2,211 & 1,136 & 799 \\
Area of inundation $\left(\mathrm{m}^{2}\right)$ & 955000 & 950000 & 937500 & 932500 \\
\hline
\end{tabular}

The results in Table 3 show that an increase in the manning's $n$ (friction coefficient) cause decrease in the debris flow velocity, decrease in depth of flow and also a decrease in the impact force (a measured of hazard intensity). This is expected due to the increase in the basal friction of the flow with increase in the friction coefficient 
thereby reducing the velocity of flow. The total volume of debris deposit increased with increased in friction coefficient (Table 3 ) and this may be because with low velocity, deposition takes places.

The most sensitive parameter to the friction coefficient is the velocity of flow, this may be due to the fact that as the friction coefficient increases, the resistance to flow is increased and this tends to reduce the velocity of flow. This also affect the impact force, since the velocity is reduced with increase in the friction coefficient, the impact force will reduce.

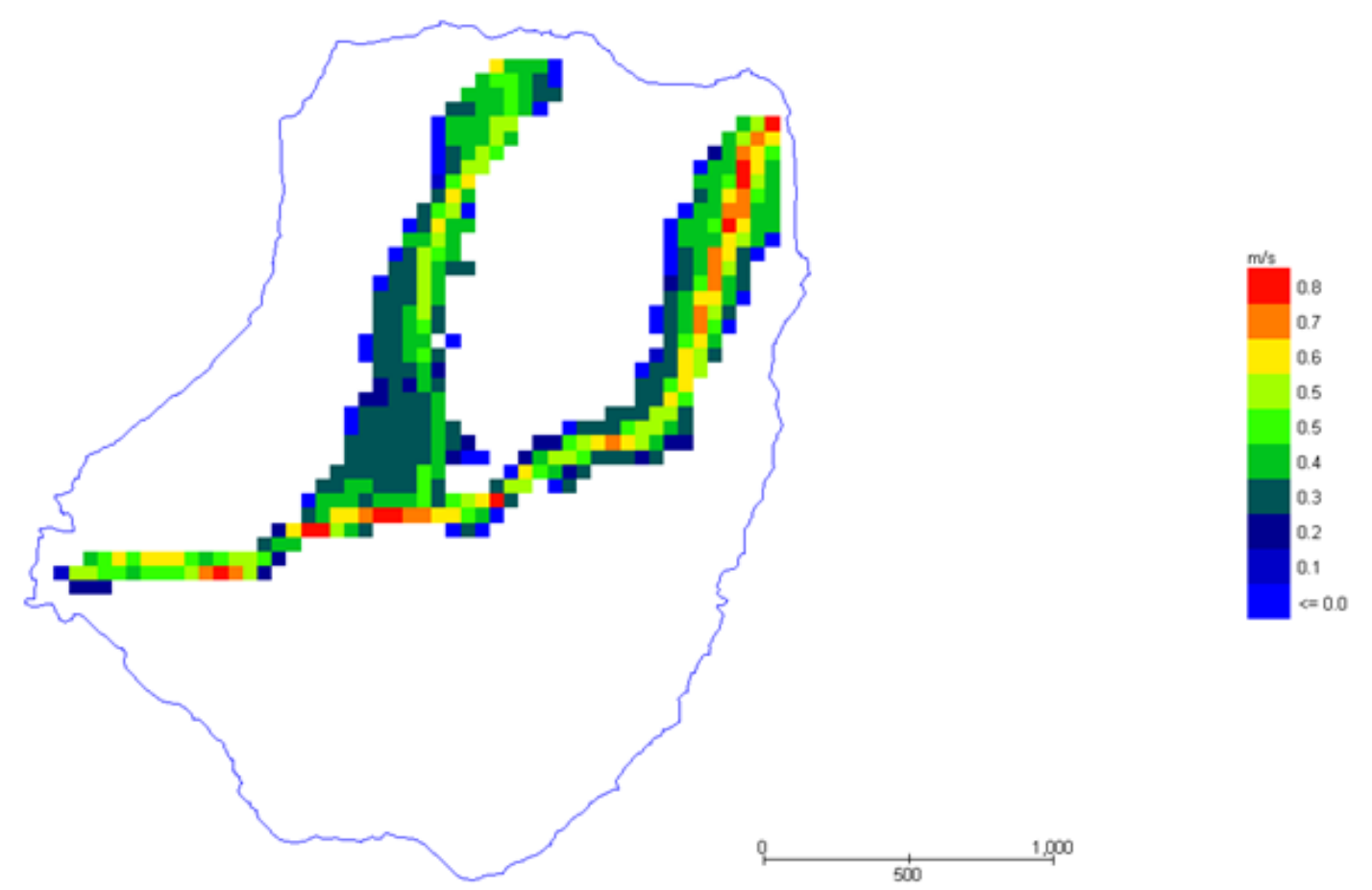

Figure 13. Debris flow grid maximum velocity

\subsubsection{Sensitivity to Viscousity Coefficient and Yield Stress}

Changing the viscosity coefficient and yield stress while keeping the concentration constant (and other parameters) has shown little changes on the total volume of the debris flow. The researcher observed that, there were no changes in the area extent of the debris, the flow depth, velocity and specific energy the exact reasons for this are not known by the researcher.

\subsection{Calibration of Result}

Calibration is an important part of modeling of debris flows .It implies, trying to spatially replicate past events or predicts future ones. The aim of calibrating models is to adjust the parameters of the model so that the modeled results replicate real observed events and thus determine the range of values of the parameters.

Due to lack of well documented modeling results for the catchment and limited field measurement of the debris flow event, a back analysis of the debris flow event, was carried out using the total debris flow volume of $250,000 \mathrm{~m}^{3}$ from interview (the only available information of the 2010 event). The calibrated volume from the FLO-2D model was $161,350 \mathrm{~m}^{3}$. This result represents $64.54 \%$ reconstruction of the debris flow event. This result (debris flow volume of $161,350 \mathrm{~m}^{3}$ ) does not include entrainment. This is a limitation of the FLO-2D model. Entrainment is an important debris flow process that increases debris flow volume (Hussin, 2011).

The application of calibration criteria in a back analysis of the debris flow events have shown that, they are useful in replicating the debris flow similar to the August 14th, 2010 event in the catchment. Furthermore, the use of literature values instead of field determined data may have some short comings in the model results.

\section{Conclusion}

The earthquake triggered landslides which in turn, generated debris (landslides bodies). The debris flow initiated in two areas of the catchment and these areas represent susceptible zones. The debris materials were saturated by 
antecedent rainfall due to high porosity and permeability of the soil. The numerous faults and steep nature of the catchment topography amongst the other mentioned factors led to the remobilization of the materials as debris flow. The volume of the debris flow modeled was $161,350 \mathrm{~m}^{3}$ and it represents $64.54 \%$ of the debris flow volume for the catchment. This was done in a manner consistent within the limit of the data available and limit of the model. The model does not incorporate entrainment of materials in the transport zone. Thus, limitation to the production of the total deposits volume on the debris flow fan. The model was parameterized and the result shows that Sediment concentration and the coefficient of friction were the two main parameters that the model was sensitive to. Thus, they affected the velocity of debris flow, area of inundation and the impact force respectively. Finally, the debris flow was calibrated using a back analysis of the debris flow event of 2010. Literature values used in determining the viscosity parameters, yield stress parameters and the sediment concentration may not represent catchment reality. Hence, further research need to be carried out to ascertain this parameters for the catchment.

\section{Acknowledgements}

We are greatly indebted to the Dutch government, for providing funding for the research. Special thanks to Prof. Tang Chuan and Prof. Zhu Jing of the Chengdu University of Technology, China for their immense assistance with some data. Special thanks to Prof Fu. Xiaomin and Zheng Hai Jun, for their assistance during the laboratory analysis at Chengdu University of Technology (CDUT) laboratory in China.

\section{References}

Abulohom, M. S., Shah, S. M. S., \& Ghumman, A. R. (2001). Development of a Rainfall-Runoff model, its calibration and validation. Water Resources Management, 15, 149-163. http://dx.doi.org/10.1023/A:1013069709740

Aleotti, P. (2004). A Warning System for Rainfall-induced Shallow failures. Engineering Geology, 73(3-4), 247-265. http://dx.doi.org/10.1016/j.enggeo.2004.01.007

Cesca, M., \& D'Agostino, V. (2006). Comparison between FLO-2D and RAMMS in debris flow Modeling: a case study in the Dolomites. International Conference on Monitoring simulation, prevention and remediation of Dense and Debris flow II, 60, 161-168.

Chigira, W. M., Furuya, W. T., \& Kamai, T. (2003). Geological Causes and Geomorphological precursors of the Tsaoling Landsildes Triggered by the 1999 Chi-Chi earthquake, Taiwan. Engineering Geology, 68, 259-273. http://dx.doi.org/10.1016/S0013-7952(02)00232-6

Christen, M., Kowalski, J., \& Bartelt, P. (2010). RAMMS: Numerical Simulation of Dense snow-avalanches in three dimensional terrains. Cold Regions Science and Technology, 63(1-2), 1-14. http://dx.doi.org/10.1016/j.coldregions.2010.04.005

Cui, P., Zhu, Y. Y., Han, Y. S., Chen, X. Q., \& Zhuang, J. (2009). The 12 May Wenchuan-Induced Landslides: Distribution and Preliminary Risk Evaluation. Landslides, 6, 209-223. http://dx.doi.org/10.1007/s10346-009-0160-9

Dai, F. C., Lee, C. F., \& Ngai, Y. Y. (2002). Landslide risk assessment and management: an overview. Engineering Geology, 64(1), 65-87. http://dx.doi.org/10.1016/S0013-7952(01)00093-X

FLO-2D manual. (2007). FLO-2D Software Inc. Nutrioso. Retrieved August 1, 2011, from www.flo.2d.com/information/description.htm

Glade, T., Michael, C., \& Peters, S. (2000). Applying Probability Determination to Refine Landslide-Triggering Rainfall Thresholds Using an Empirical Antecedent Rainfall Model. Pure and Applied Geophysics, 157, 1059-1079. http://dx.doi.org/10.1007/s000240050017

Huang, R. Q., \& Li, W. L. (2008). Analysis of the Geo-hazards Triggered by the 12 May 2008 Wenchuan Earthquake, China. Bull Eng Geol Environ, 68, 363-371. http://dx.doi.org/10.1007/s10064-009-0207-0

Hussin, H. Y. (2011). Probabilistic Run out Modeling of Debris in Barcelonnette, France. MSc. Thesis, University of Twemte (ITC Faculty, Enschede), 60.

Keefer, D. K. (1984). Landslides Caused by earthquakes. Geological Society of America Bulletin, 95, 406-421. http://dx.doi.org/10.1130/0016-7606(1984)95<406:LCBE>2.0.CO;2

Khazai, B., \& Sitar, N. (2004). Evaluation of Factors Controlling earthquake-Induced Landslides caused by Chi-Chi earthquake and Comparison with the Northbridge and Loma Prieta evnets. Engineering Geology, 71, 79-95. http://dx.doi.org/10.1016/S0013-7952(03)00127-3 
Kowalski, J. (2008). Two-phase Modeling of debris flows. Ph.D Thesis. Swiss Federal Institute of Technology, Zurich.

Lan, H., Wu, F., Zhou, C., \& Wang, L. (2003). Spatial Hazard Analysis and Prediction on Rainfall-Induced Landslide using GIS. Chinese Science Bulletin, 48, 703-709. http://dx.doi.org/10.1360/03tb9150

Lin, Q., Liu, S., \& Liu, C. (2006). Impacts of the Chi-Chi Earthquake on subsequent Rain-Induced landslides in Central Taiwan. Engineering Geology, 86, 87-101. http://dx.doi.org/10.1016/j.enggeo.2006.02.010

Moradkhami, H., \& Sorooshian, S. (2009). General Review of Rainfall-Runoff Modeling: Model Calibration, Data Assimilation and Uncertainty Analysis. In N. S. Sorooshian, K. L. Hsu, E. Coppola, B. Tomassetti, M. Verdecchia, \& G. Visconti (Eds.), Hydrological Modeling and the Water Cycle. Berlin, Springer.

O'Brien, J. S., Julien, P. Y., \& Fullerton, W. T. (1993). Two-dimensional water flood and Mudflow simulation. $\begin{array}{lllll}\text { Journal of Hydraulic } & \text { Engineering, } & 119(2), & \text { 244-261. }\end{array}$ http://dx.doi.org/10.1061/(ASCE)0733-9429(1993)119:2(244)

Petrascheck, A., \& Kienholz, H. (2003). Hazard Assessment and hazard mapping of Mountain Risk-examples of Switzerland in: Debris flows Hazard Mitigation: Mechanics, Prediction and Assessment. 3rd International DFHM conference, Davos, Switzerland, September 10-12, Rotterdam, Mill press, 25-38.

Quan Luna, B. (2007). Assessment and Modeling of two Lahars caused by 'Hurricane Stan' at Atitlan, Guatemala, October, 2005. MSc. Thesis, University of Oslo, Oslo.

Tan, W., \& Hen, Q. (1992). Study on Regional Critical Rainfall Induced Debris flow in Sichuan Province. Journal of Catastrology, 7, 37-42 (in Chinese).

Tang, C., Zhu, J., Qi, X., \& Ding, J. (2011). Landslides Induced by the Wenchuan earthquake and the subsequent rainfall event. A case study of in the Beichuan area of China. Engineering Geology, 12.

Van Asch, T. W. J., Buma, J., \& Van Beek, L. P. H. (1999). A Review on Some hydrological triggering systems in Landslides. Geomorphology, 30, 25-32. http://dx.doi.org/10.1016/S0169-555X(99)00042-2

\section{Copyrights}

Copyright for this article is retained by the author(s), with first publication rights granted to the journal.

This is an open-access article distributed under the terms and conditions of the Creative Commons Attribution license (http://creativecommons.org/licenses/by/3.0/). 